\title{
A continuidade pós-separação: necessidades comuns aos ex-cônjuges e seus filhos
}

\section{The continuing post-separation: the common needs of ex- spouses and their children}

\section{Sofia Débora Levy*}

Doutoranda do Programa de Pós-Graduação em História das Ciências, Tecnologias e Epistemologia/COPPE, Universidade Federal do Rio de Janeiro - UFRJ, Rio de Janeiro, RJ, Brasil

\begin{abstract}
RESUMO
No presente artigo, na interface das áreas Clínica e Jurídica em Psicologia, pretendemos demonstrar que, apesar do advento da Lei do Divórcio na sociedade brasileira, com vias a oportunizar a desconstrução e reconstrução de laços familiares mais construtivos, a destrutividade já então presente nas relações entre os ex-cônjuges e seus filhos assumiu novas formas de violência. As graves conseqüências para todos os envolvidos urgem ser abordadas, delineadas e cuidadas pelas áreas da Psicologia e do Direito. Apresentamos contribuições no âmbito da psicologia existencial, de modo a evidenciar algumas necessidades comuns aos indivíduos como limiar para uma convivência familiar construtiva.
\end{abstract}

Palavras-chave: Ex-conjugalidade, Parentalidade, Violência, Integridade psíquica.

\begin{abstract}
This article, in the interface of clinical and lawyer psychology, intend to demonstrate that, in spite of the income of the law of divorce, in order to allow the deconstruction and reconstruction of families, in a more constructive way, the destructivity, that had already been there, between ex-husbands and ex-wives and their children, has assumed new forms of violence. The awful consequences to all of them must be urgently boarded, delineated and handled by Psychology and Law. Existential Psychology contributions about human needs are presented as a threshold for a constructive familiar living together.
\end{abstract}

Keywords: Ex-conjugality, Parenthood, Violence, Psycho integrity.

\section{Separação não deve ser sinônimo de destruição}

Nas últimas décadas, temos observado e acompanhado um grande número de casais que, mesmo após a separação, continuam a se relacionar de modo negativo, e por vezes até passam a se referir e a tratar o ex-cônjuge de modo absolutamente destrutivo, assumindo posturas radicais de oposição, com requintes de perversidade (HIRIGOYEN, 2002), conforme amplamente demonstrado pela mídia. 
Para além de momentos extemporâneos de raiva, ciúme, revolta, observamos um modelo socialmente estabelecido e aceito de rivalidade, revanchismo, desrespeito à integridade, descaso e abandono, supostamente justificável pelo término da relação conjugal ${ }^{1}$.

Frente à dificuldade em continuar a viver recebendo a todo tempo deboche, distorção, ódio, desamor de quem uma vez já fora o(a) companheiro(a) físico, emocional, mental, questionamos: Por que não continuar a tratar bem? Por que preferir alimentar sentimentos e idéias falsas sobre o outro - sentimentos e idéias que não existem na história factual vivida familiarmente?

Notadamente após o advento da Lei do Divórcio, ampliou-se a naturalidade com que tais comportamentos têm sido socialmente aceitos. O divórcio passa a ter caráter legal no Brasil em 26 dezembro de 1977 (Lei 6.515) buscando trazer uma nova possibilidade de convivência familiar sem atitudes desonrosas entre as partes (KOSOVSKI, 1983). Infelizmente, o que temos assistido é que, com as separações, têm aumentado ainda mais as condutas desonrosas e a violação dos direitos humanos (RAJ NEESH, [ca.1986]), dificultando a digna reconstrução da integridade de cada cônjuge e de sua prole.

No presente trabalho, nosso intuito não é nos determos na culpabilização dos agentes causadores dos prejuízos psíquicos advindos dos tipos de violência familiar de nossos dias. Buscamos, sim, evidenciar as trágicas lesões psíquicas que se instalam prejudicando o funcionamento e desenvolvimento cognitivo e afetivo dos indivíduos (em qualquer faixa etária) visando, através da conscientização dos mesmos, um repensar dos comportamentos conjugais - em especial pós-conjugais - e parentais, contribuindo, assim, para a melhoria na qualidade de vida e bem-estar individual e social.

\section{Ex-Conjugalidade e Parentalidade}

Formalmente, definiríamos conjugalidade e parentalidade como o exercício dos papéis conjugais e parentais, respectivamente. No entanto, isso pouco nos diz face às condições sociais em que vivemos: uma era em que a conjugalidade não é mais estudada a partir de um único modelo de família, e seus papéis são reconfigurados diante das mais diversas demandas sociais (SARTI, 1993). Com pais e mães trabalhando fora de casa, e com um número crescente de casais separados, à difícil e múltipla compreensão da parentalidade acrescentaríamos a noção de ex-conjugalidade como uma condição necessária de ser enfocada para melhor apreendermos as possibilidades e dificuldades atuais nos relacionamentos de pais e mães entre si, e estes com seus filhos - em comum e/ou de outros relacionamentos. 
A ex-conjugalidade tem se expressado de diversas formas, das mais afáveis e educadas formas de convivência amigável, até o extremo oposto, com comportamentos agressivos criminosos - ilustrados pela mídia. Uma vez desfeito o modelo tradicional de família, as relações conjugais e parentais tornaram-se mais vulneráveis às condições múltiplas de afetividade e personalidade de cada um de seus componentes. Não há uma uniformidade de tratamento postulada por modelos sociais. Assim, torna-se necessário um maior grau de tolerância de parte a parte para a manutenção de uma convivência não-destrutiva. Pela dificuldade de reconstrução de identidade que cada separação implica, isso não tem sido uma tarefa fácil (BAUMAN, 2005). Com isso, a superficialidade e os comportamentos destrutivos também aparecem como formas de tratamento entre ex-cônjuges - e até sendo socialmente aceitas e incorporadas à cultura vigente.

A parentalidade varia de acordo com a estrutura social vigente em dado momento histórico, com seus modelos sociais e educacionais peculiares, e com valores que irão influenciar na estruturação das relações entre pais e filhos. Em nossa sociedade atual, as relações parentais assumem diversas formas de manifestação, pela multiplicidade de modelos das famílias recasadas (BRITO, 2007).

Enquanto a paternidade refere-se à condição biológica pela herança genética transmitida na procriação, marcada pela consangüinidade, a parentalidade, por sua vez, implica um conjunto de relações, ligadas à afiliação, numa conjugação complexa de fatores históricos, psicológicos, sociais, afetivos, econômicos e jurídicos. Envolve vontade de aprender e de conviver com o outro (SILVA, 2004).

As dificuldades no cumprimento das relações de parentalidade são inúmeras. Não apenas pela sua complexidade, mas também pelas diversas transformações sociais que a sociedade contemporânea tem apresentado quanto às formas de estruturação básica, ou seja, quanto às possíveis formas de relação familiar, suas características peculiares e conseqüências micro e macrossociais (FÉRES-CARNEIRO, 1999).

\footnotetext{
Assim, a criança, em seu desenvolvimento, constrói e parentaliza seus pais, demandando-Ihes uma constante autoredefinição no tempo e na relação com o mundo e com os outros.

Por outro lado, a função parental sofre a influência de circunstâncias diversas, entre as quais podemos citar: a história de vida de cada um dos pais, a sua relação com os próprios pais no passado e no presente, a percepção de si mesma(o) como mãe/pai e como pessoa e a dinâmica de sua vida atual. (SILVA, 2004, p. 9)
}

Diante dessa complexidade, com a separação e suas conseqüências jurídicas, muitos adultos se vêem mais inseguros, hoje em dia, para 
exercerem papéis parentais de forma equilibrada e satisfatória para si e para os filhos. Sentem o impacto das reestruturações de identidade e de estruturas econômicas e as dificuldades parecem crescer cada vez mais. Diante de tantos conflitos, as emoções não canalizadas satisfatoriamente tendem a ser extravasadas sob forma de violência (MAY, 1978).

\title{
Formas de violência
}

\begin{abstract}
O demônio desmembra a realidade, desmonta-a, acaba por reduzi-la a um punhado de peças isoladas. Até aí chega ele, sem tropeços maiores. Mas, no instante de unir, de congregar os laços que ligam - ou religam - os elementos disjuntos, então falha, de maneira grotesca. (PELLEGRINO, 1989 , p. 121)
\end{abstract}

No mundo atual, a violência tomou formas cada vez mais sutis e menos explícitas. Não é difícil reconhecermos uma violência em sua forma explícita, seja verbal ou física. O mesmo já não acontece com a violência perversa. Nas últimas décadas, a psicanálise francesa vem se debruçando sobre a violência perversa, buscando preencher essa lacuna de difícil nominação pela gravidade do quadro físico e psicológico conseqüente das manipulações ideativas, afetivas e históricas. Segundo Marie-France Hirigoyen (2006), "a violência perversa se caracteriza por uma hostilidade constante e insidiosa" ( $p$. $67)$.

A violência perversa é violência em estado puro. Ela pode infiltrar-se no espírito do outro, a fim de levá-lo a se autodestruir. Esse movimento mortífero prossegue mesmo na ausência daquele que o pôs em marcha, e não pára nunca. [...] Chega a ser contagioso e é um risco dos grandes: as vítimas ou as testemunhas podem começar também a transgredir, a perder seus referenciais. (HIRIGOYEN, 2006, p. 68)

Cunhada pela psicanalista Marie-France Cyr, na Bouderie (CYR, 2001) - em francês, amuo, enfado -, a arma é o silêncio. Nessa forma de violência perversa silenciosa, uma das partes se recusa tácita, contínua e absolutamente em dialogar com o outro envolvido na situação. Na bouderie, a intersubjetividade é negada. E, como atesta o termo em francês, a atitude é de quem está amuado, enfadado, desagradado frente à situação. O desprezo, o descaso, a falta de investimento, interesse e paciência estão presentes na atitude do agente, o boudeur.

Concomitante a essa negação de diálogo com o outro, o boudeur, promovedor do silêncio imposto, passa a ter comportamentos que denigrem seu alvo, falando sobre ele, mas nunca com ele. Calúnias e 
distorções são, muitas vezes, relatadas a terceiros na forma de ironias finas, e passam a compor a história acerca da vítima, moldando um quadro no qual o boudeur, nessas suas narrativas sobre si e sobre o outro, se imiscui de qualquer caráter negativo de personalidade.

Assim, o boudeur utiliza-se de estratégias indiretas de ação, de tal modo a proteger suas ações culposas, e com isso se defendendo de outras possíveis testemunhas e olhares críticos. Seu estado enfadado busca ganhar apoio de terceiros por ele estar sendo incomodado pelo outro, a quem nega e contém silenciosamente. Projeta e imputa à própria vítima motivos que justificam sua diminuição. Busca angariar a aquiescência social quanto às suas ações e modos de interpretar os fatos por ele narrados. Nessa perspectiva, até a própria existência da relação chega a ser negada!

A arma utilizada sempre é não deixar a vítima ser ouvida, ter voz (CYR, 2001; HIRIGOYEN, 2002). Uma vez negado à vítima o direito de se defender e argumentar, esta acaba implodindo em suas forças reativas e criativas, sufocando-se numa dinâmica auto-destrutiva que Ihe é imposta.

A negação, a indiferença à dor do outro gerando uma capa de mentira intermediária entre quem sente a dor e os que a cercam sabedores dessa dor, mas não querendo se debruçar sobre ela negam à vítima essa condição ao negar a sua dor. E negam a ela a oportunidade de se manter em contato consigo mesma, pois se há um lugar onde nos sabemos e nos identificamos conosco mesmos é nas nossas emoções.

Ao invés de apreender esta condição básica do funcionamento humano, as pessoas, nas mais diversas culturas, passaram a fazer uso de critérios racionalizados de julgamento acerca das emoções alheias e dos comportamentos a elas relacionados.

A empatia não mais foi considerada em seu aspecto primordial para o bom entendimento do indivíduo consigo e com os outros.

O estarrecimento da vítima frente à impossibilidade de ter legitimada a sua dor por quem quer que seja, a mantém na angústia múltipla: a do problema propriamente dito, acrescida da incompreensão e da impossibilidade de sentir a dor pela cobrança de um comportamento diferente frente à mesma; e pela indiferença e descaso de quem a sabe.

Como podemos ultrapassar a dor quando ela é negada, distorcida, debochada, minimizada por terceiros, e estes mesmos cobram da vítima um comportamento natural e espontâneo, como se nada tivesse acontecido?... A vítima ainda é muitas vezes culpabilizada como se quisesse, desejasse se manter na dor. A indiferença dos implicados no problema, aliada à indiferença dos outros que a cercam - inclusive no âmbito judicial -, cria uma atmosfera quase de 
inatingibilidade de sua dor e do problema do qual todos são sabedores! Nas palavras de Hirigoyen (2002):

Quando as vítimas querem ajuda, é comum que não sejam ouvidas. Não é raro analistas aconselharem as vítimas de um ataque perverso a verificarem até que ponto elas próprias foram responsáveis pela agressão que sofreram.

(HIRIGOYEN, 2002, p. 14)

Pela dificuldade do ser humano em entrar em contato com a dor - de si e do outro - e com seu potencial destrutivo, distorções e inverdades sobre a história individual e coletiva tornam-se lugar comum. O quanto isso dificulta o apaziguamento entre as partes, apenas depois de muita dor, às vezes, é reconhecido.

\section{A Normose}

Um dos fatores mais alarmantes nesse vasto quadro de formas de violência é a naturalidade com que tal destrutividade vem sendo aceita, introjetada e incorporada às nossas relações sociais. Admitese que estamos vivendo uma cultura individualista, mas que não há um mal tão grande nisso. Haveria até conseqüências positivas, pois não se sofre mais por culpa como antes - assim se diz amiúde.

A infelicidade que cada um sabe dentro de si, ladeia com a fuga às reflexões profundas sobre o ser. A superficialidade e a cobrança de resultado aumentaram e são os parâmetros vigentes entre todos. Perguntamos se o ser humano tem se dado conta de seu afastamento do próprio saber de sua possibilidade de renovação sensível e afetiva. Há tempos, o psicólogo Roberto Shinyashiki (1991) vem alertando para a necessidade de trocas pessoais com base no afeto, como nosso alimento básico psicológico. Pierre Weil (2003) chega a cunhar o conceito de Normose para designar a normalidade da patologia que nos assola sócio-culturalmente, ou seja, a naturalidade com que as pessoas vêm aceitando os maus-tratos sob a forma de violência silenciosa, assédio moral, desprezo, deboche... Na França, Lipovetsky (2005), na Filosofia, e Hirigoyen (2006), na Psicanálise, entre outros autores, desde a década de 90 vêm dando destaque aos quadros de perversão de valores morais velados que assolam as relações micro e macrossociais, buscando traduzir o que a maior parte das pessoas não consegue, seja por inacessibilidade a um parâmetro mais saudável, seja pela dificuldade de elaboração inerente ao desamparo vivido internamente, que não sabe a quem e aonde gritar sua dor.

A qualidade e intensidade da dor advinda do desprezo à própria possibilidade de existir significativamente para o outro, promove uma auto-rejeição que mantém o indivíduo enfraquecido e descrente, desejando, sem saber como, resgatar a motivação e a vontade de investir na vida. 
Parar, e de braços cruzados, assistir impassível a avalanche seguir, ao léu, é negar o valor de cada um influindo nos destinos da humanidade!

Grande pecado a omissão. O SIM que não foi dado, equivale a um NÃO em altos brados. Um ponto positivo a menos.

Viver, simplesmente por viver, indiferente aos outros e ao mundo, sem opinar, sem deliberar, é mais cômodo e mais fácil, mas não é o certo.

Omitir-se, é se juntar aos que lutam contra.

O omisso e o pessimista caminham de braços dados. Ele se omite porque não acredita nem em si, e nem nos outros. Não se julga com valor suficiente para fazer frente aos que the são contrários. Por isso cruza os braços e deixa o barco correr, à sua própria sorte. Com o risco de naufragarem todos.

Se a responsabilidade está em cada um, longe o ceticismo e a omissão. (STELLA, 1976, p. 104)

\section{Prejuízos à integridade psíquica}

A perspectiva existencial em Psicologia compreende o ser em sua capacidade de se aperceber e se conscientizar de seus pensamentos e de suas emoções, enfocando o ser humano numa perspectiva ontológica (LEVY, 1996). O entendimento da dinâmica psicológica do indivíduo na esfera dos três mundos Umwelt (mundo natural), Mitwelt (mundo social) e Eigenwelt (mundo individual), é a referência da Psicologia Existencial. O ser humano vive simultaneamente os três mundos e apresenta três modos simultâneos de ser no mundo (MAY, 1991).

Se o indivíduo é impedido de se manifestar em um deles, os outros dois são diretamente afetados. Portanto, a Psicologia Existencial propõe que o indivíduo tome consciência das implicações de suas ações nesses três níveis, pois aí reside o senso de responsabilidade aliado à capacidade que cada um tem de se fazer frente a si, aos outros e ao mundo ao redor.

O Umwelt é o mundo natural, que todos os organismos possuem, uma vez que é da ordem das necessidades biológicas, dos ciclos naturais de nascer e morrer, dormir e acordar. O Mitwelt é o mundo dos relacionamentos entre os seres humanos. Aqui, os mecanismos de ajustamento e adaptação do Umwelt não satisfazem as necessidades do indivíduo. Não se trata de se adaptar, mas de cada indivíduo se perceber em suas relações interpessoais, nas quais as dinâmicas que lhes são próprias evidenciam a necessidade de transformação recíproca de todas as partes envolvidas, como ilustra Rollo May:

Se eu insisto para que outra pessoa ajuste-se a mim, não a estarei tomando como pessoa, mas como instrumento; e, mesmo que eu me ajuste a mim próprio, estarei usando a 
mim mesmo como objeto. [...] A essência do relacionamento é que no contato ambas as pessoas apresentem uma mudança. (MAY, 1991, p. 141)

O Eigenwelt, exclusivo dos seres humanos, pressupõe autoconsciência e é onde o homem pode pensar a si, aos outros e ao mundo ao redor, e aperceber-se da singularidade da construção desse entendimento. É onde o indivíduo irá conhecer-se em sua condição original de como vê e vive nestes três mundos.

Sendo capaz de compreender e se aceitar frente às suas potencialidades e limitações (Eigenwelt), o homem também passa a ser capaz de compreender as potencialidades e limitações dos outros (Mitwelt). A aceitação de sua condição inacabada e dinâmica propicia uma postura mais humilde frente ao outro, uma vez que não há uma verdade ou um entendimento absoluto da condição humana. Conseqüentemente, o respeito à existência e às verdades do outro é um exercício passível de ser constantemente realizado para uma melhor compreensão e alocação de si e dos outros no entendimento da realidade.

Segundo Maslow (1974), um modo de entendimento do ser humano se dá exatamente penetrando na Weltanschauung (visão de mundo) do outro, isto é, buscando "ver o seu mundo através de seus olhos" (p. 62).

Acrescentaríamos, continuando este processo de reflexão, que o indivíduo é capaz de se aperceber do quanto a sua Weltanschauung se modifica a partir do entendimento do outro. É nas trocas do Mitwelt que o indivíduo se apercebe em seu Eigenwelt e com isso se apresenta ao Umwelt.

Infelizmente, toda essa bela apreensão da dinâmica psíquica do ser humano fica prejudicada em seu funcionamento básico quando as relações parentais e conjugais (notadamente as ex-conjugais) são negadas em suas possibilidades positivas de manifestação. 0 conjunto de feedbacks mutuamente necessários deixa de existir quando os contatos são negados de forma absoluta, como nos casos de abandono, negativas de diálogo, de encontro, de toque. A localização básica consciente do indivíduo frente aos três mundos fica lábil pela falta de trocas que reafirmem a identidade essencial do indivíduo (self), prejudicando o desenvolvimento de sua personalidade. Conseqüentemente, as capacidades afetivas e cognitivas ficam prejudicadas, podendo, inclusive, regredir, no caso dos adultos, e ter seu desenvolvimento pleno não realizado, no caso de crianças e jovens em idade de maturação e desenvolvimento físico e psíquico.

Os processos mente-corpo são todos co-dependentes das condições às quais o indivíduo se encontra inserido, tanto no Umwelt, quanto no Mitwelt. Qualquer separação traz mudanças na organização da vida 
dos membros da família. O esforço para que essas mudanças se processem com menos prejuízos na capacidade de cada um se entender nos novos contextos deve ser mister em cada um dos mesmos.

Após a separação, as histórias de vida tanto dos pais quanto dos filhos continuam dentro de uma nova organização. O combate à descontinuidade de contato é fundamental para que cada um possa se acompanhar em seus possíveis reposicionamentos - os quais aqui propomos que sejam pautados sem se perder de vista no que têm de melhor em cada indivíduo e em cada relação. Fundamental é o respeito de cada parte às possibilidades positivas de relação entre cada subgrupo dos membros da família original. Não destruir o que se sabe positivo na relação dos outros que lhes são próximos, ainda que numa reconfiguração que os distancie mais habitacionalmente.

A reconstrução da identidade individual se faz necessária com o acompanhamento histórico de cada indivíduo consigo e frente aos que o cercam. O retorno do outro, compartilhando as etapas dessa transição, propiciam acomodações gradativas em que se torna mais fácil aceitar e compreender aos outros e a si nas novas condições. Tanto os pais quanto os filhos passam a precisar uns dos outros ainda mais, no sentido de poderem reconfirmar, a cada momento, seu valor, sua pertencença e sua importância na vida uns dos outros. Sem o acompanhamento histórico mútuo, em suas significações individuais e biunívocas, o indivíduo fica cindido de si e dos outros, o que gera um quadro de angústia permanente, recheada de dor e tristeza de difícil nominação pois seus conteúdos se encontram abaixo do patamar mínimo de referência básica de humanidade em suas condições ontológicas. É como se o indivíduo tivesse de evidenciar e nominar seu não-ser, impedido de ter sua vida historicamente realizada, confirmada e registrada pelo outro com quem compartilha essa mesma realidade histórica na qual se sabe - ou se saberia existindo, se assim lhe fosse permitido ser reconhecido tranqüila e espontaneamente.

Se cada um se sabe em condições de poder colaborar na difícil transição, não lhe cabe recriar situações sabidamente destrutivas e prejudiciais, seja por inabilidade em lidar com a própria dor, com as próprias dificuldades inerentes à separação e reconfiguração dos laços conjugais e parentais, ou por um modismo cultural que, frente a essas mesmas dificuldades individuais, recrudesceu em justificativas que, ao invés de solucioná-las, apenas as reforçou, contribuindo para uma sociedade contemporânea adoecida pela falta de afetividade.

Urge a revisão frente ao legado transmitido para as futuras gerações, cada vez mais carentes e buscando, sem saber como, retomar um bem-estar básico na condição de ser vivente. A necessidade permanece em aberto, até que possa reencontrar seus elos de continuidade específicos junto àqueles com quem compartilha dessas 
mesmas quebras de continuidade. Tal é a condição humana de busca de equilibração de suas condições existenciais e significativas para se sentir vivo.

O demônio é espertíssimo - como se a esperteza pudesse ter a última palavra. Ele falsifica, engana, semeia a cizânia, apunhala o diálogo, promove a desagregação de tudo. Mas tudo, teimosamente, se interliga - se religa -, os dedos se tocam, as mãos se entrelaçam, os braços se abraçam, os corpos se unem, matéria atrai matéria. Nesse jogo, o demônio perde a guerra. (PELLEGRINO, 1989, p. 123-124)

\section{O aporte ao Direito e à Psicologia}

Na interface da Psicologia e do Direito, trazemos um outro problema à tona: o estudo das partes - advogados de cada parte, réu, requerente, peritos, assistentes técnicos,... - que se formam e aprendem a construir a apresentação de dados organizados de acordo com os critérios instituídos pelo fórum do Direito, nos quais a complexidade relacional deve se enquadrar de modo a manter a formalização da apresentação e compreensão regular dos diversos casos em Vara de Família (RAMOS, 1994).

À Psicologia Jurídica caberia, dentre outras sugestões e intentos, buscar ampliar cada vez mais o diálogo com profissionais da área do Direito, com vistas à sua aproximação da realidade atualizada, num esforço de superação de termos e conceitos arraigados e preconceituosos, que dificultam o alcance da verdade histórica comum às partes. Um exemplo estaria na importância de se averiguar a origem, o início do litígio, colaborando, assim, para que se possa identificar a intenção original de cada parte - atribuição do psicólogo inserido no Tribunal de Justiça. Isso porque, uma arma amiúde utilizada nos jogos judiciais, dentre outras tantas, é a culpabilização do outro, denegrindo-o, como tentativa de se ver e ser visto como bom. Nesses jogos, em conformidade com as formalidades de apresentação e atuação no âmbito do Direito, a busca da verdade histórica tem cedido espaço à melhor articulação de convencimento.

Alertamos para esse enrijecimento acerca do comportamento entre as partes, notadamente ex-cônjuges, que passa a ser cobrado nas disputas nos tribunais; é de tal artificialismo que a espontaneidade que havia na convivência fica perdida em lugar de olhares necessariamente contrários e rivalizantes acerca de comportamentos tidos por anos como aceitáveis, com o único intuito de ganhar uma disputa, em especial referente às necessidades do cumprimento das prerrogativas estabelecidas pelo Estatuto da Criança e do Adolescente quanto ao bem-estar, formação e cuidados para com o menor - ECA, Lei Federal $n^{\circ} 8069 / 90$ de 13/07/1990 (BRASIL, 2003). Conviver cede lugar a competir. Mas nesse caso, todos perdem - a não ser 0 
orgulho, a vaidade e o egoísmo, que insistem em se manter na falsa alimentação imagística, que esconde dores e incompreensões, rotuladas erroneamente de fraquezas.

Ao demônio é impossível unir o que quer que seja, pois the falta bondade. O amor, segundo Dante, é a força que move o sol e as estrelas. A conjunção dos seres humanos, tanto quanto a dos astros na harmonia das esferas, é fruto de Eros. Eros conjuga, configura, complexifica, totaliza. Se a união faz a força, Eros é forte - e o demônio, fraco. A inteligência verdadeira é erótica, se fundamenta no amor. A bondade, fora de qualquer dúvida, é a forma superior de inteligência. Se pretendo conhecer um objeto, é necessário que me abra para ele, para que no espaço da abertura que Ihe ofereço possa advir sua desocultação. O surgimento da verdade do objeto que quero conhecer é conseqüência do amor pelo qual con-sinto em sua existência.

É isto que o demônio, em escala absoluta, não sabe fazer. Ele funda, portanto, o lugar do desconhecimento máximo - da máxima mentira. A verdade é relação, enredamento, tecido de pertinências que se entretecem. Só me conheço na exata proporção em que esteja constitutivamente referido a um par que não sou eu. O demônio está condenado, por toda a eternidade, a não ter relação com quem quer que seja. Ele é infinitamente isolado, píncaro de solidão que sequer se reconhece como tal: o sentimento da própria solidão já é uma nostalgia - uma aragem - do Próximo. (PELLEGRINO, 1989, p. 122- grifo nosso)

A Justiça fica comprometida, sujeita à perspicácia de juízes e promotores, também estes inseridos no mesmo conjunto de normas arraigadas e enrijecidas. Difícil se torna, para os ex-cônjuges e para os filhos, obterem ajuda eficaz da Justiça, de modo a se resgatarem em qualidades mínimas de bons tratos, diminuindo a maledicência corrosiva das relações. Nesse estado atual, a atuação na esfera jurídica ainda tem se dado mais no incremento das competições do que nas cooperações.

\section{Conclusão}

A partir de sua implementação, o Estatuto da Criança e do Adolescente - ECA - trouxe um grande avanço para o trato junto ao menor de idade ao delinear uma série de cuidados físicos e psicológicos necessários para o seu desenvolvimento ótimo. Concordamos que esta seja uma saída básica emergencial a ser intentada. Mas o cumprimento dessas condições propostas depende da ação de cada pai e cada mãe para o seu cumprimento. E apenas mantendo-se a visão de bem-querer e não de revanchismo no que tange à relação dos ex-cônjuges é que poderemos reestruturar 
positivamente a parentalidade, realizando de fato e viabilizando os moldes postulados pelo ECA.

Conforme assinalado por Marília Lobão Ribeiro (1999), acrescentaríamos que, além da importância da boa convivência entre ambos os ex-cônjuges para com os filhos após a separação, nossa sociedade deveria postular também a manutenção da necessidade de boa convivência e zelo entre os ex-cônjuges também.

O bem-estar de um ex-cônjuge para com o outro, mesmo após a separação, deveria ser estimulado em nossa base educacional, moral e ética, posto que são duas pessoas que conhecem bem uma à outra e que a anulação de uma prática de vida em que não sejam considerados e contemplados esses conhecimentos mútuos causa cortes e descontinuidades na capacidade e possibilidade de reorganização em cada cônjuge quanto ao sentido histórico, vivencial e existencial de suas histórias de vida em comum e em separado (suas identidades antes, durante e depois do casamento).

Esta dificuldade criada e mantida é um dos fatores tensionantes que acabam por dificultar também o olhar compreensivo sobre os filhos, criando e mantendo neles cisões em relação a si mesmos e a cada um dos pais. A fluência afetiva e a expressão espontânea ficam comprometidas nos três mundos configurados pela Psicologia Existencial - Eigenwelt, Mitwelt e Umwelt (MAY, 1991)-, em função das fraturas nessas relações de base.

Tanto a parentalidade quanto a ex-conjugalidade devem ser revisitadas, clarificando a dinâmica entre essas duas condições sóciofamiliares e suas implicações quanto aos descuidos ou aprimoramentos delas advindos.

A sua maneira de ser é só sua e você pode decidir de um modo ímpar, em relação ao todo.

Mas, embora únicos, não vivemos separados.

Fazemos parte de um bloco, uma gigantesca engrenagem, que depende de cada um, isoladamente.

Há uma ligação constante e permanente, de cada um com o todo.

O mundo, a humanidade, dependem da minha decisão, da sua ação, do meu espírito, da sua inteligência, do meu otimismo, da sua compreensão, do seu amor.

Se você se esquivar, se você negar a sua parte, haverá uma lacuna e ninguém poderá preenchê-la. (STELLA, 1976, p. 1314)

A mudança de valores nos indivíduos formadores de uma sociedade é lenta e descontínua, pelos próprios embates entre as partes envolvidas na desconstrução e reconstrução de suas novas estruturas. O que sugerimos, nos moldes promovidos pela relação empática no reconhecimento da integralidade do outro (BUBER, 1977), é que não se percam de vista os limites básicos de respeito 
ético para que a própria condição de sobrevivência de ex-cônjuges e de seus descendentes possam se dar de modo menos destrutivo, a partir da conscientização de necessidades básicas comuns a todos os seres humanos, em seus aspectos físicos, psíquicos, afetivos, visando o bem-estar e a saúde integral.

\section{Referências Bibliográficas}

BAUMAN, Z. I dentidade. Rio de J aneiro: J orge Zahar Editor, 2005. BRASI L. Estatuto da criança e do adolescente. Edição atualizada. Rio de Janeiro: Imprensa Oficial do Estado do Rio de Janeiro, 2003. BRITO, L. T. (Org.). Temas de psicologia jurídica. Rio de Janeiro: Relume-Dumará, 1999.

. Família pós-divórcio: a visão dos filhos. Psicologia ciência e profissão, Brasília, v. 27, n. 1, p. 32-45, 2007.

BUBER, M. Eu e tu. São Paulo: Moraes, 1977.

CYR, M-F. Arrête de Bouder! ces gens qui refusent de communiquer. Québec: Les Éditions de L'Homme, une division du groupe Sogides, 2001.

DILTHEY, W. Teoria das concepções do mundo. Lisboa: Edições 70, 1992.

FÉRES-CARNEIRO, T. (Org.). Casal e família - entre a tradição e a transformação. Rio de J aneiro: Nau, 1999.

HIRIGOYEN, M. F. Assédio Moral - a violência perversa no cotidiano. Rio de Janeiro: Bertrand Brasil, 2002.

A Violência no casal. Rio de Janeiro: Bertrand Brasil, 2006.

KOSOVSKI, E. Adultério. Rio de J aneiro: Codecri, 1983.

LEVY, S. D. Repensando o ser - uma análise metaprocessual dos relatos de sobreviventes do holocausto. 1996. 255f. Dissertação (Mestrado em Psicologia) - Instituto de Psicologia, Universidade Federal do Rio de Janeiro, Rio de Janeiro.

LIPOVETSKY, G. A. Era do vazio - ensaios sobre o individualismo contemporâneo. Barueri: Manole, 2005.

MASLOW, A. H. Psicologia existencial - o que há nela para nós?, 1974. In: MAY, R. Psicologia existencial. Porto Alegre: Globo, 1974, p. 57-66.

MAY, R. Psicologia existencial. Porto Alegre: Globo, 1974.

Eros e repressão: amor e vontade. Petrópolis: Vozes, 1978.

A descoberta do ser. Rio de Janeiro: Rocco, 1991.

PÉLLLEGRINO, H. A burrice do demônio. 4.ed. Rio de Janeiro: RocCo, 1989.

RAJ NEESH, B. S. Sobre os direitos humanos básicos. Porto Alegre: Naim, [ca.1986]

RAMOS, M. (Org.). Casal e família como paciente. São Paulo: Escuta, 1994.

RIBEIRO, M. L. A psicologia judiciária nos juízos que tratam do direito de família no tribunal de justiça do Distrito Federal, 1999. In: BRITO, 
L. T. (Org.). Temas de psicologia jurídica. Rio de Janeiro: RelumeDumará, 1999, p. 161-170.

SARTI, C. Família e individualidade: um problema moderno, 1993. In: CARVALHO, M. C. B. (Org.). A família contemporânea em debate. São Paulo: EDU/Cortez, 1995, p. 39-49.

SHINYASHIKI, R. A carícia essencial. 35.ed. São Paulo: Gente, 1991.

SILVA, M. C. P. (Org.). Ser pai, ser mãe: parentalidade: um desafio para o novo milênio. São Paulo: Casa do Psicólogo, 2004.

STELLA, R. O reto e o oblíquo - um ensaio sobre a vivência humana. 2.ed. Brasília: Senado Federal Centro Gráfico, 1976.

WEI L, P.; LELOUP, J-Y; CREMA, R. Normose - a patologia da normalidade. Campinas: Verus, 2003.

\section{Endereço para correspondência}

Sofia Débora Levy

Programa de Pós Graduação em História das Ciências das Técnicas e Epistemologia

- HCTE, Centro de Tecnologia/UFRJ, Avenida Athos da Silveira Ramos, 149, Bloco

A, $7^{\circ}$ andar, CEP 21941-909, Cidade Universitária, I lha do Fundão, Rio de J aneiro - RJ, Brasil

Endereço eletrônico: sofiadebora@hotmail.com

Recebido em: 30/09/2008

Aceito para publicação em: 30/04/2010

Acompanhamento do processo editorial: Eleonôra Torres Prestrelo

\section{Notas}

* Psicóloga Clínica, Membro da Sociedade Brasileira de Vitimologia - SBV, Mestre em Psicologia/UFRJ/1996, Curso de Extensão em Psicologia Jurídica IBH/2008, Autora (Org.). de Atrás de minhas pegadas (GARAMOND, 2006) e Sobre Viver (Relume-Dumará, 2006).

${ }^{1}$ No presente artigo consideramos cônjuges o casal que mantem relação estável em cohabitação, tendo ou não o registro civil de certidão de casamento. 